\title{
TREATMENT OF ACUTE LEPROTIC NEURITIS WITH HYALASE AND CORTISONE
}

by R. H. Thangaraj, M.B.B.S. and Mrs. Sarojini Thangaraj, M.B.B.S. The Mission to Lepers, Purulia Leprosy Home and Hospital, Purulia (West Bengal).

A total of 40 cases were treated for acute leprotic neuritis in four groups, each group consisting of 10 patients. The patients were put in the different groups by drawing lots. Only patients who had one or two attacks previously were selected for the study.

\section{Investigations}

Clinical and electrical assessments of the affected muscles were carried out every week in all the cases. The electrical assessment was done by R.A.F. type II electrical muscle stimulator. Table No. 1 shows the electrical condition of muscles before the treatment.

TABLE 1

Electrical Response of Muscles

\begin{tabular}{lcccc}
\hline Nerve & Normal & Weak & Poor & Total \\
\hline Ulnar & 23 & 5 & - & 28 \\
Lat. popliteal & 4 & 2 & - & 6 \\
Median & 3 & - & - & 3 \\
Radial & - & 1 & 1 & 2 \\
Gr. Auricular & - & - & - & 1 \\
\hdashline-\begin{tabular}{l} 
ToTAL \\
\hline
\end{tabular} & 30 & 8 & 1 & 40 \\
\hline
\end{tabular}

The swollen part of the nerve was measured by means of calipers every fourth or fif th day. The progress record was maintained by the physiotherapist.

Group A: 1,000 units of Hyalase dissolved in $1 \mathrm{ml}$. of $1 \%$ Lignocaine was injected intraneurally to this group of patients. The second injection was repeated after 4 days. Only in two cases a third injection was repeated.

Group B: $0.5 \mathrm{ml}$. of cortisone acetate ( $12 \frac{1}{2} \mathrm{mgm}$.) with 1,000 units of Hyalase in $1 \mathrm{ml}$. of $1 \%$ Lignocaine was administered intraneurally to this group. The second injection was repeated after four days. 
Group C: Only $1 \mathrm{ml}$. of $1 \% \%$ Lignocaine was administered to this group intraneurally. This group was taken as a control group. A second injection was repeated after four days.

Group D: This group was given intravenous pot. antimony tartrate on alternate days with an initial dose of $0.02 \mathrm{~g}$. gradually increasing to $0.05 \mathrm{~g}$. Distilled water was injected subcutaneously over the affected nerve to this group. Groups A. B. and C. were given a placebo replacement of pot. antimony tartrate (sterile $1 \%$ glucose solution was used for the purpose). This was to satisfy the psychology of the patient.

TABLE 2

\begin{tabular}{lccccc}
\hline Nerves & A & B & C & D & Total \\
\hline Ulnar & 5 & 7 & 8 & 8 & 28 \\
Lat. popliteal & 3 & 1 & 1 & 1 & 6 \\
Median & 2 & - & - & 1 & 3 \\
Radial & - & 1 & 1 & - & 2 \\
Gr. Auricular & - & 1 & - & - & 1 \\
\hline \multicolumn{1}{c}{ Total } & 10 & 10 & 10 & 10 & 40 \\
\hline
\end{tabular}

In the case of lat. popliteal neuritis the limb was immobilized with the knee in full extension and the foot in dorsiflexion. No immobilization was done in the case of other nerves. Of the 40 cases 38 were lepromatous and two were dimorphous.

\section{Results}

TABLE 3

Showing the Progress after the Treatment

\begin{tabular}{lccccc}
\hline Groups & $\begin{array}{c}\text { Complete } \\
\text { relief }\end{array}$ & $\begin{array}{c}\text { Partial } \\
\text { relief }\end{array}$ & No relief & $\begin{array}{c}\text { Muscles } \\
\text { Paralysed }\end{array}$ & $\begin{array}{c}\text { Relief after } \\
\text { stripping }\end{array}$ \\
\hline A & 6 & 2 & - & 1 & 1 \\
B & 8 & 1 & - & 1 & - \\
C & 5 & 1 & - & 1 & 3 \\
D & 6 & 2 & 1 & - & 1 \\
\hline
\end{tabular}

The best results were obtained with group $\mathrm{B}$. The notable thing in this group was the complete recovery of the radial nerve. The patient was not able to lift his wrist against resistance. The electrical condition of the affected muscles was very poor. In the last case of this group the patient developed foot drop immediately after the injection into the lat. popliteal nerve. This was a case of dimorphous 
leprosy and the muscles which were normal before the injection never recovered. In another case of dimorphous leprosy Hyalase was administered with Lignocaine, but without success. The results with potassium antimony tartrate and Hyalase were also good but in the control group as many as three nerves had to undergo nerve stripping.

FolLOw-UP: As we carried out this trial mainly on our inpatients, 36 patients were available for follow-up studies after eight months. Table 4 will show the electrical condition of muscles and the relapse rate in each group.

TABLE 4

\begin{tabular}{lccccc}
\hline Groups & Relapse & Normal & $\begin{array}{c}\text { Condition of Muscles } \\
\text { Weak }\end{array}$ & $\begin{array}{c}\text { Paralysed } \\
\text { Not available }\end{array}$ \\
\hline A. & 2 & 6 & - & 2 & 2 \\
B. & 1 & $* 8$ & - & 1 & 1 \\
C. & 2 & 6 & 1 & 3 & - \\
D. & 4 & 7 & 1 & 1 & 1 \\
\hline
\end{tabular}

* This also includes the great auricular nerve.

From the above tables we found that the results from group B were very good. I agree that the results will vary very much if all the cases of leprotic neuritis (virgin cases and those who have had repeated attacks) are put on these drugs. Since we started the series with cortisone acetate two years ago this was continued till the end but the results with Hydrocortisone may be still better.

\section{Discussion}

We must mention in full the very interesting comment made by Dow in an article on the late results of decapsulation as long ago as 1936. His comment reads as follows: "In the light of the results which have followed upon operations on thickened nerves, we now feel justified in resorting to surgery only in cases of nerve abscess and only exceptionally in these cases it is necessary to decapsulate the nerve. The best results are generally obtained by exposing the abscess, removing the caseous material and closing without drainage. In all other cases of nerve enlargement the practitioner will be well advised to cling to the less spectacular but in the long run more satisfactory medical forms of treatment, for he will find that nerve decapsulation does not realize the hopes raised and its end results are apt to be anything but satisfactory".

In the Purulia Leprosy Home which has 840 inmates and 6,000 out-patients, we resort to stripping only in the following cases:

1. Patients who do not respond to medical means. 
2. Tuberculoid nerve reaction when the function of the nerve is threatened.

3. Gradual deterioration in the electrical condition of the affected muscles in lepromatous leprosy.

4. In some cases of dimorphous leprosy.

From the literature we find that several drugs have been tried both intraneurally and subcutaneously along the nerve with variable success.

In 1936 Cochrane and Paulraj tried injection of $80 \%$ alcohol intraneurally in two cases with good results.

In 1938 Gass tried cobra venom parenterally with good results. It is interesting to note that snake venom contains hyaluronidase.

Alexander in 1944 tried injection of $25 \%$ magnesium sulphate around the nerve. He observed that the effect of the injection lasted for 2-3 months.

Horan in 1949 reported about the successful results obtained from nerve block with $0.15 \%$ pontocaine solution with $1 / 200,000$ epinephrine.

Garret in 1956 used Hyalase intraneurally in few cases with encouraging results. The injections were given once weekly and a course of five injections was used as a standard.

In 1957 Jopling and Cochrane tried Hydrocortisone with provaine intraneurally in few cases and later Jopling reported on a case of foot drop in which he administered intraneural Hyalase and Hydrocortisone in procaine solution. The lat. popliteal nerve completely recovered.

In a paper read at the regional conference of the Mission to Lepers at Purulia in 1958, Thiessen reviewed the different measures in the treatment of acute neuritis.

Hyalase increases the tissue permeability and disperses the oedema. Cortisone is a fibrolytic agent and also reduces the capillary permeability thus reducing the oedema.

According to Brand the nerve during the inflammatory stage should be rested in its stretched position. The tissues of the nerve contract and fibrosis takes place during the resolving stage of inflammation. If immobilization is done in its contracted position it ruptures when stretched causing more damage to the nerve.

It is also interesting to note that Hyalase or the combination of Hyalase and cortisone did not have any effect on dimorphous nerves. In one case it actually did harm.

Though the series is small and confined only to certain types of cases, it is evident from the results obtained that a combination of Hyalase and cortisone in lignocaine solution has a definite beneficial effect in acute neuritis. 


\section{References}

1. Alexaniser, V. P. "Treatment of neural symptoms in Leprosy". (1944) Leprosy in India, 16, 10.

2. Cochrane and Paulraj. "Alcohol injections for the relief of nerve pain in leprosy”. (1937) Leprosy in India, 9, 18.

3. Dow, D. P. "Late results of nerve decapsulation in leprosy". (1936) Leprosy in India, 8, 113.

4. Garret, A. S. "Hyalase injection for lepromatous nerve reaction". (1956) Leprosy Review”. 27, 61.

5. Gass, H. H. "Cobra Venom in Leprous Neuritis". (1938) Leprosy in India, $10,37$.

6. HORAN, J. S. "Treatment of lepra reaction and acute neuritis and arthritis with nerve block and intravenous administration of procaine." (1949), I.J.L., 17, 211.

7. Jopling, W. H. and Cochrane, R. G. "The place of cortisone and corticotrophin in the treatment of certain acute phases of leprosy". (1957) Leprosy Review, 28, 5.

8. Jopling, W. H. "Corticosteroids in the management of foot drop in lepromatous leprosy”. (1959). Leprosy Review, 30, 171.

9. Thiessen, A. D. “Acute Neuritis in Leprosy. A Review”. (1959) Leprosy in India, 31, 3. 